Article

\title{
Modeling and Dynamic Analysis on the Direct Operating Solenoid Valve for Improving the Performance of the Shifting Control System
}

\author{
Xiangyang $\mathrm{Xu}{ }^{1,2}$, Xiao Han ${ }^{1,2}$, Yanfang Liu ${ }^{1,2, *}$, Yanjing Liu ${ }^{1,2}$ (1) and Yang Liu ${ }^{3}$ \\ 1 School of Transportation Science and Engineering, Beihang University, Beijing 100191, China; \\ xxy@buaa.edu.cn (X.X.); hanxiaoook@163.com (X.H.); liuyanjing@buaa.edu.cn (Y.L.) \\ 2 Beijing Key Laboratory for High-efficient Power Transmission and System Control of New Energy Resource \\ Vehicle, Beihang University, 37 Xueyuan Road, Haidian District, Beijing 100191, China \\ 3 Research Department of Vehicle Chasis, Beijing Institute of Space Launch Technology, Beijing 100076, China; \\ kaka19881019@126.com \\ * Correspondence: liuyf@buaa.edu.cn; Tel.: +86-139-1009-9728
}

Received: 7 November 2017; Accepted: 1 December 2017; Published: 5 December 2017

\begin{abstract}
The dynamic characteristics and energy loss in a shifting control system is important and necessary in the performance improvement of an automatic transmission. The direct operating solenoid valve has been considered as a potential component applying in the shifting control system in vehicle. The previous method can solve only a specific physical field or use the test results of the magnetic force as input curve. The paper presents a numerical approach for solving the multi-domain physical problem of the valve. A precise model of the direct acting solenoid valve considering different physical field is developed. An experimental study is also performed to evaluate and confirm the simulation. Based on the model, the influences on the dynamic characteristics of the valve are analyzed by calculating forces acting on the valve. The systematic analysis of forces and energy loss characteristics are performed for three different flow conditions varying clearance height from $10 \mu \mathrm{m}$ to $30 \mu \mathrm{m}$. The results demonstrate that the pressure response time can be improved with smaller clearance between the spool and the sleeve. Moreover, the leakage of the shifting control system employing the direct acting solenoid valve can be reduced by $60 \%$ compared to the conventional two-stage pilot valve in our previous product.
\end{abstract}

Keywords: direct operating solenoid valve; energy loss; forces; response pressure; leakage flow

\section{Introduction}

To shift from one gear to another in an automatic transmission, one clutch needs to be released and another needs to be applied. The shifting control system of the automatic transmission controls the clutch pressure and the corresponding transmitted torque during shifting process. The dynamic characteristics of the shifting control system are directly related to the shifting quality. Figure 1 is the conventional structure of a shifting control system consisting of a relieve valve, a pilot solenoid valve and a clutch control valve. In this structure, the automatic transmission fluid passes through several valves and complicated oil lines from the main line to the clutch. The long passage causes the delayed pressure response, low control accuracy and big leakage. 


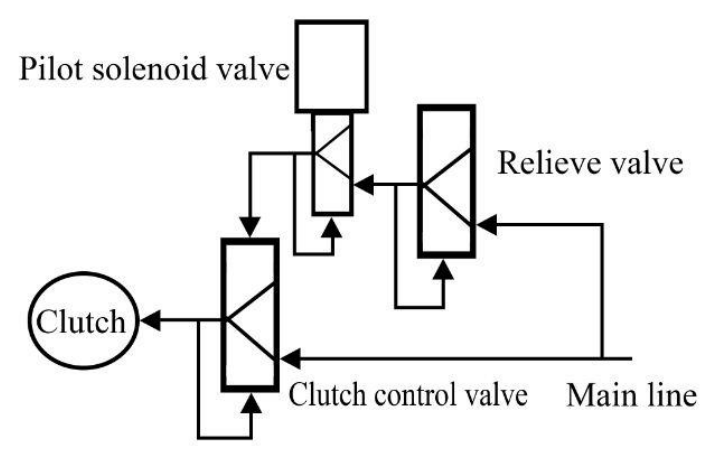

Figure 1. Conventional structure of the shifting control system.

With the development of the industry, a new pressure valve called direct operating solenoid valve could take place of the conventional two-stage structure for its small leakage, large flow, high reliability and high control accuracy. Figure 2 is the structure of the shifting control system applying the direct operating solenoid valve. It is obvious that simple structure and light weight of the system can be obtained by utilizing this kind of structure which has been more and more adopted in the latest automatic transmission. The direct operating valves are produced by many well-known worldwide companies such as Tosok, Bosch, Highlight and Narchi. Improving the characteristics of the valve can directly contribute to the performance of the shifting control system. Hence, a growing interest in direct operating valves emerges from scientific centers.

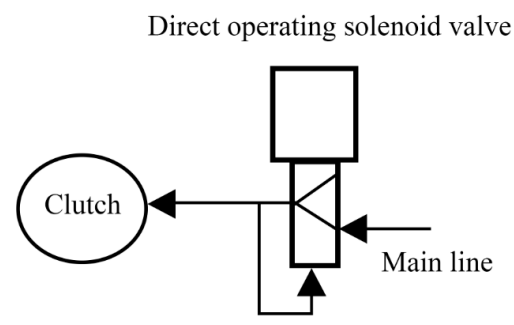

Figure 2. Structure of the shifting control system applying the direct operating solenoid valve.

Presently, many studies on the solenoid valve are focused on a specific physical field such as the magnetic field or the flow field. Shuai Wu et al. [1] proposed a new direct drive valve which has high frequency voice coil motor and advanced digital controller. A digital controller and a hybrid controller were developed to control the valve motion and were indicated to improve the control accuracy and robustness of the system through test. The static characteristics of the electromagnetic linear actuators were analyzed by A. Schultz [2]. 3D electromagnetic fields analysis of the electromagnet was carried out using ANSYS. Influence factors such as working area, coil turns, core number, armature depth and iron material that affects the magnetic force were discussed in detail. The influencing law to the magnetic force was obtained [3]. Liu Qianfeng et al. [4] reported that the electromagnetic force of the direct action solenoid valve was mostly influenced by the current. Optimization of the design parameters of the valve was achieved by complex method. The control accuracy of the magnetic force could be well improved based on the studies. Yujeong Shin et al. [5] adapted Ansys Maxwell electromagnetic analysis software to model the electromagnetic dynamics and selected the best optimization model using the verified approximation model. However, the dynamic characteristic of the valve could not be adequately enhanced if we only study the magnetic force because a sensitive pressure response is caused by the interaction of the resultant force.

Multi-physics coupling models were reported in many studies. The valves were usually designed as compact constructions, which contain a mechanical part, a hydraulic part and an electronic controller in a single module. Gee Soo Lee et al. [6] carried out a three-dimensional numerical 
simulation employing a moving mesh with dynamic layering meshes for varying boundary conditions to investigate the flow dynamic behavior and pressure characteristics of a variable force solenoid valve. Klaus Mutschler et al. [7] presented an alternative approach using network simulation methods to model a dispensing valve using a simulation software SABER. The model could correctly predict the dispensed liquid volume in dependence of the main parameters like pressure and opening time. Another multi-physics modeling method was introduced by Liu Yanfang et al. [8]. They successfully predicted the dynamic characteristics of a proportional solenoid valve and used it for valve design. Liu Z. et al. [9] optimized the structure of a large flow solenoid valve by multi-physics modeling method. Yi Xiong et al. [10] extended the dynamic model of the high-response dual proportional solenoid valve discontinuous projection-based adaptive robust control to synthesize controller to deal with the parametric uncertainties and uncertain nonlinearities. Both the simulation and experimental results showed the proposed controller was effective. The nonlinear characteristic, the orifice area and the dynamic model of the solenoids were also analyzed using Matlab by Yaguang Zhu and Bo Jin [11]. Meanwhile, Liu Lei et al. [12] analyzed the influences of throttle nozzles' diameter and other parameters on the dynamic and static characteristics of a low-pressure large-flow pilot-operated solenoid valve via AMESim simulation software. And optimization was conducted in the model. Chang-Dae Park et al. [13] provided a convenient method of design verification of solenoid operated valve. Lan Wang et al. [14] found that firing current, holding current, spring pre-tightening force and spring stiffness had great effects on the dynamic response characteristics of solenoid valve. An electromagnetic mathematical model of a high-speed solenoid valve was developed in Fortran language. Jianhui Zhao et al. [15] discovered that the electromagnetic energy conversion characteristics of the HSV were affected by the drive current and the total reluctance, consisting of the gap reluctance and the reluctance of the iron core and armature soft magnetic materials. Paul D. Walker et al. [16] established mathematical models of the integrated electrohydraulic solenoid valve and wet clutch piston assembly in the Simulink environment of Matlab. The dependency of the system to system variables on input pressure and the influence of air content on dynamic response of the valve were investigated.

Though an amount of work has been done on the direct operating solenoid valve, there still exist several shortcomings in previous studies. The magnetic force obtained from the tests is input directly into the model rather than real-time computing which would result in the capability of analyzing the magnetic force. Forces, including the magnetic force, play a very important role in a direct operating valve because they have strong relation to both the pressure response and the leakage. Therefore, it is essential to introduce a multi-physics method which could compute all forces in real time and predict the dynamic characteristics of the direct operating solenoid valve.

In this paper, a multidisciplinary approach was conducted to obtain the dynamic characteristics of the direct operating solenoid valve. According to the approach, the simulation model of the valve was developed using the minimum element method. Secondly, experiments have been conducted on the test rig in order to verify the numerical results. The experimental results showed good agreement with the simulated ones, which confirm the accuracy of the simulation model. Thirdly, based on the model, the influencing factors including forces, critical size and leakage flow on the performance of the valve were detailed and analyzed. Finally, suggestions are proposed to improve the performance of the direct operating solenoid valve, which could be effective for the valve design.

\section{Valve Structure and Principle}

The direct operating solenoid valve is composed of mechanical subsystem, electro-magnetic subsystem and hydraulic subsystem as shown in Figure 1. The electro-magnetic subsystem is composed of coil, armature and tube. The mechanical subsystem consists of a sleeve in which a spool and a spring are located inside. The position of the spool is mainly determined by an electromagnetic force, a spring force and a feedback force arising from the pressure difference of the orifice. 
The solenoid valve under study is a direct operating solenoid valve manufactured by Tosok (Kanagawa Prefecture, Japan). The valve is kept at its closed position by the return spring if there is no input current (Figure 3a). The control port is connected to the exhaust port.
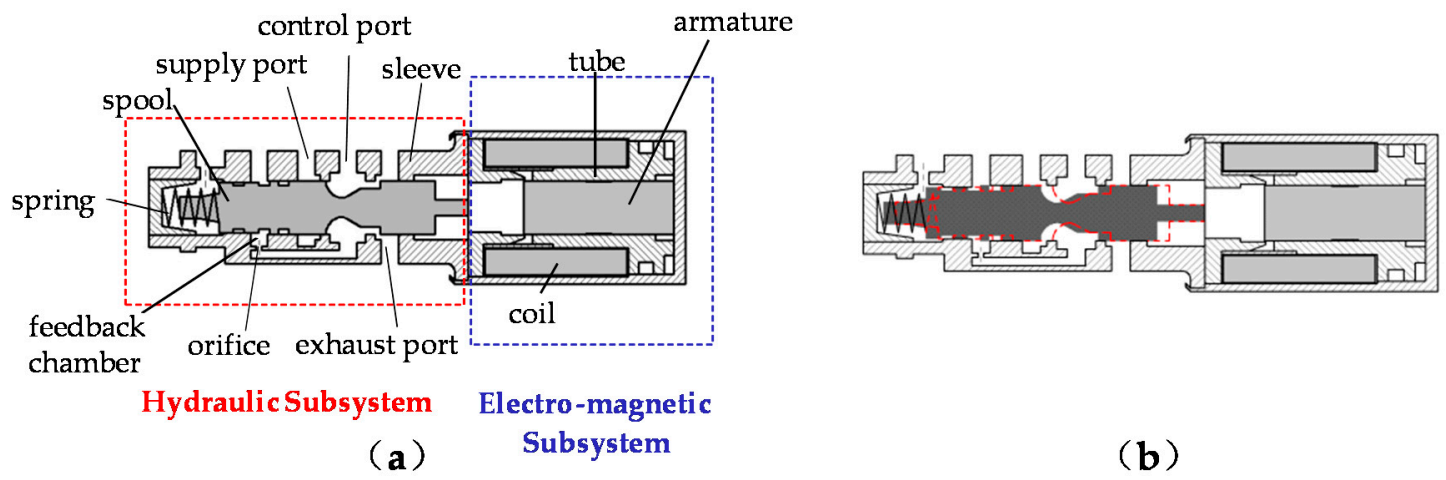

Figure 3. (a) Structure of the direct operating solenoid valve (b) Working principle of the valve.

When the solenoid is energized, the magnetic force actuates the spool to move against the return spring. Then the supply port opens where the transmission fluid flows through to the control port. Meanwhile, the exhaust port is closed, and the fluid enters the control port to reach precise control pressure and finally flows to the clutch as shown in Figure 3b. Likewise, the fluid discharging from the clutch reenters the valve through the control port and flows to the tank as the electric current disappears and the spool returns to its initial position.

\section{Modeling}

A direct operating solenoid valve is a multi-physics system with characteristic of strong nonlinearity. Different subsystems of the valve are investigated and expressed in nonlinear state equations.

In the model, the outflow direction is assumed to be positive. The variables in mathematical model are scalars during calculation. However, the flow direction will be prejudged before solving the system equation.

\subsection{Electro-Magnetic Subsystem}

The magnetic force is the driving force of the direct operating solenoid valve which is generated by the magnetic circuit when electric current is input. The magnetic circuit is formed of a fixed core surrounded by the coil turns and an armature connected to the spool which moves with the spool under the effect of the exerted magnetic force.

According to Kirchhoff's Voltage Law, the following equation must be held for each loop in the magnetic circuit:

$$
\sum V_{m, n}=\sum \Phi_{n} \cdot R_{m, n}=0
$$

where $V_{m, n}$ is the magnetic voltage, $\Phi_{n}$ is the magnetic flux, $R_{m, n}$ is the magnetic resistance.

With the definition of the magnetic flux, the following statement is applied to any connection between these components of the magnetic circuit:

$$
\sum \Phi_{i}=0
$$

From the first equation of Maxwell, the electric field could be expressed as follows:

$$
\oint H \cdot d s=\theta
$$


where $H$ is the magnetic field strength.

The relationship between magnetic field and electric field is

$$
V_{m}=\theta=w \cdot i
$$

where $w$ is the winding number, $i$ is the electric current.

In the electromagnetic field, the electric voltage difference $V_{E i}$ consists of the voltage drop and the induced voltage.

$$
V_{E i}=R_{E i} \cdot i+w \cdot \frac{d \Phi}{d t}
$$

where $R_{E i}$ is the electric resistance.

According to the following fundamental relations:

The magnetic field intensity $B$ is

$$
B=\frac{\Phi}{A_{a}}
$$

where $A_{a}$ is the area of air gap.

The magnetic field strength is

$$
H=\frac{V_{m}}{l}
$$

where $l$ is the air gap length.

The magnetic resistance $R_{m}$ can be stated as

$$
R_{m}=\frac{l}{\mu_{0} \cdot A_{c}}
$$

where $\mu_{0}$ is the permeability of vacuum.

The cross-sectional area $A_{c}$ is

$$
A_{c}=\frac{\pi}{4} \cdot d^{2}
$$

where $d$ is the diameter of air gap.

The magnetic voltage is

$$
\begin{gathered}
V_{m}=R_{m} \cdot \Phi \\
H=\frac{B}{\mu_{0}}
\end{gathered}
$$

Hence, the static magnetic force is

$$
F_{m s}=\frac{1}{2} \cdot \Phi_{\text {Air }}^{2} \cdot R_{m}=\frac{1}{2} \cdot \Phi_{\text {Air }}^{2} \cdot \frac{l}{\mu_{o} \cdot A}
$$

where $\Phi_{A i r}$ is magnetic flux of airgap.

However, the air gap length will keep changing when the spool starts to move with the magnetic force. Thus, the dynamic magnetic force $F_{m d}$ is calculated as

$$
F_{m d}=\frac{1}{2} \cdot \Phi_{\text {Air }}^{2} \cdot \frac{d R_{m}}{d l}
$$

\subsection{Hydraulic Subsystem}

The electromagnetic and mechanical parts of the valve are used to control the flow through the valve orifice by controlling the spool position. The flow balance of the supply line can be described as

$$
\dot{p}_{\text {out }}=\frac{\beta}{V_{\text {out }}}\left(Q_{\text {sup }}-Q_{\text {con }}-Q_{f b}\right)
$$


where $\dot{p}_{\text {out }}$ is the output pressure, $\beta$ is the buck modulus of the hydraulic fluid, $V_{\text {out }}$ is the volume of the output port and $Q_{s u p}, Q_{c o n}, Q_{f b}$ is the flow through the supply port, control port and the feedback orifice, respectively.

The flow through the supply port is as follows [17-20]

$$
Q_{\text {sup }}=C_{d} A_{\text {sup }}\left(x_{v}\right) \sqrt{\frac{2}{\rho}\left|p_{\text {sup }}-p_{\text {con }}\right|}
$$

where $C_{d}$ is the unitless discharge coefficient, $A_{\text {sup }}$ is the area of the supply port, $x_{v}$ is the spool position, $\rho$ is the fluid density, $p_{\text {sup }}$ is the supply pressure and $p_{\text {con }}$ is the control pressure.

The flow through the control port is given as

$$
Q_{c o n}=C_{d} A_{c o n}\left(x_{v}\right) \sqrt{\frac{2}{\rho} p_{c o n}}
$$

where $A_{\text {con }}$ is the area of the control port.

As the control port feeds to the clutch piston cylinder, the initial pressure $P_{c l u}$ should be 0 . Thus, the differential pressure in Equation (16) should be $\left|P_{c o n}-P_{c l u}\right|$, simplified as $P_{c o n}$.

There exists an orifice which connects with the control port to regulate the output pressure because of the choking effect. The feedback force from the orifice is large enough to be one of the most important influence factors of the spool kinstate. Equation (17) is used to calculate the orifice flow.

$$
Q_{f b}=C_{d} \pi r_{f b}^{2} \sqrt{\frac{2}{\rho}\left|p_{c o n}-p_{f b}\right|}
$$

where $r_{f b}$ is the radius of the orifice, $p_{f b}$ is the feedback pressure.

The dynamic behavior of pressure in the orifice can be illustrated as

$$
\dot{p}_{f b}=\frac{\beta}{V_{f b}}\left(Q_{f b}+A_{f b} \cdot \dot{x}_{v}\right)
$$

where $V_{f b}$ is the volume of the chamber from the control port to the pressure feedback area.

\subsection{Dynamics Motion}

The spool of the direct operating solenoid valve is subjected to the magnetic force, feedback force, friction force and compression spring force. Deduced from Newton's second law, the dynamic equation of the direct operating valve can be expressed as the following second order differential equation [21-25].

$$
M_{v} \cdot \ddot{x}_{v}=\left[F_{m}-F_{f b}-F_{v s}-D_{v} \dot{x}_{v}-F_{s p}\right]
$$

where, $M_{v}$ is the spool mass, $F_{m}$ is the magnetic force, $F_{f b}$ is the feedback force, $F_{v s}$ is the viscous force, $D_{v}$ is the damping coefficient, $F_{s p}$ is the spring force.

Figure 4 is the force diagram of the direct operating solenoid valve. The magnetic force is the force which is generated by the electric coil acting on the armature and is transferred on the spool. The feedback force arises when the feedback pressure in the feedback chamber acts on the end face of the spool. The viscous force appears when the spool has a tendency to move. The spring force originates from the compression of the spring. 


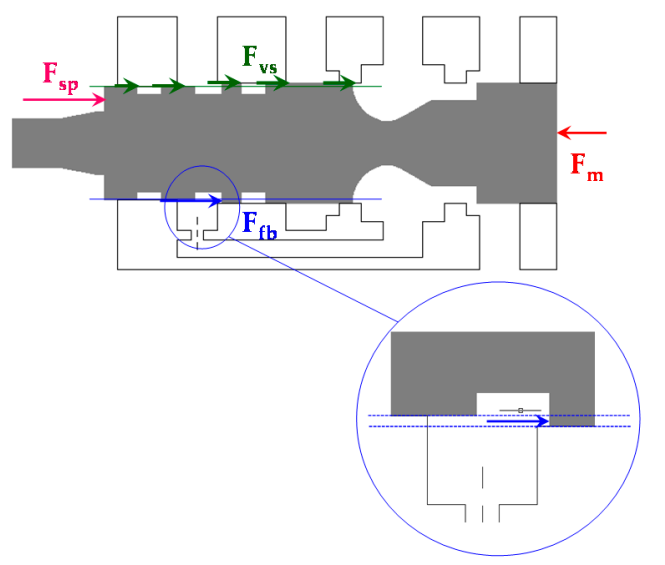

Figure 4. Force diagram of the direct operating solenoid valve.

$$
F_{v s}=\tau_{\omega} \cdot A_{\tau}
$$

where, $\tau_{\omega}$ is the wall shear stress, $A_{\tau}$ is the contact area for wall shear.

$$
\begin{gathered}
A_{\tau}=\omega \cdot l_{c} \\
\tau_{\omega}=\left(h / 2 l_{c}\right) \cdot p
\end{gathered}
$$

where, $\omega$ is the clearance width, $l_{c}$ is the clearance length, $h$ is the clearance height.

The compression spring is fixed at the end of the spool, and the spring force is

$$
F_{s p}=k_{v}\left(x_{v}+x_{v 0}\right)
$$

where $k_{v}$ is the spring coefficient.

The feedback force from orifice can be derived as

$$
F_{f b}=A_{f b} p_{f b}
$$

Simulation of the direct operating solenoid valve is developed based on the above mathematical models. The model parameters are defined according to the real geometric structure.

\subsection{The Simulation Model}

The dynamic characteristics of the direct operating solenoid valve can be accurately solved by Simulation $X$ based on the above mathematical method. The simulation model of the valve was developed adopting the minimum element method in which model parameters were defined according to the real geometric structure. And Figure 5 is a general view of the created simulation model in which the solenoid valve is detailed and modeled. 


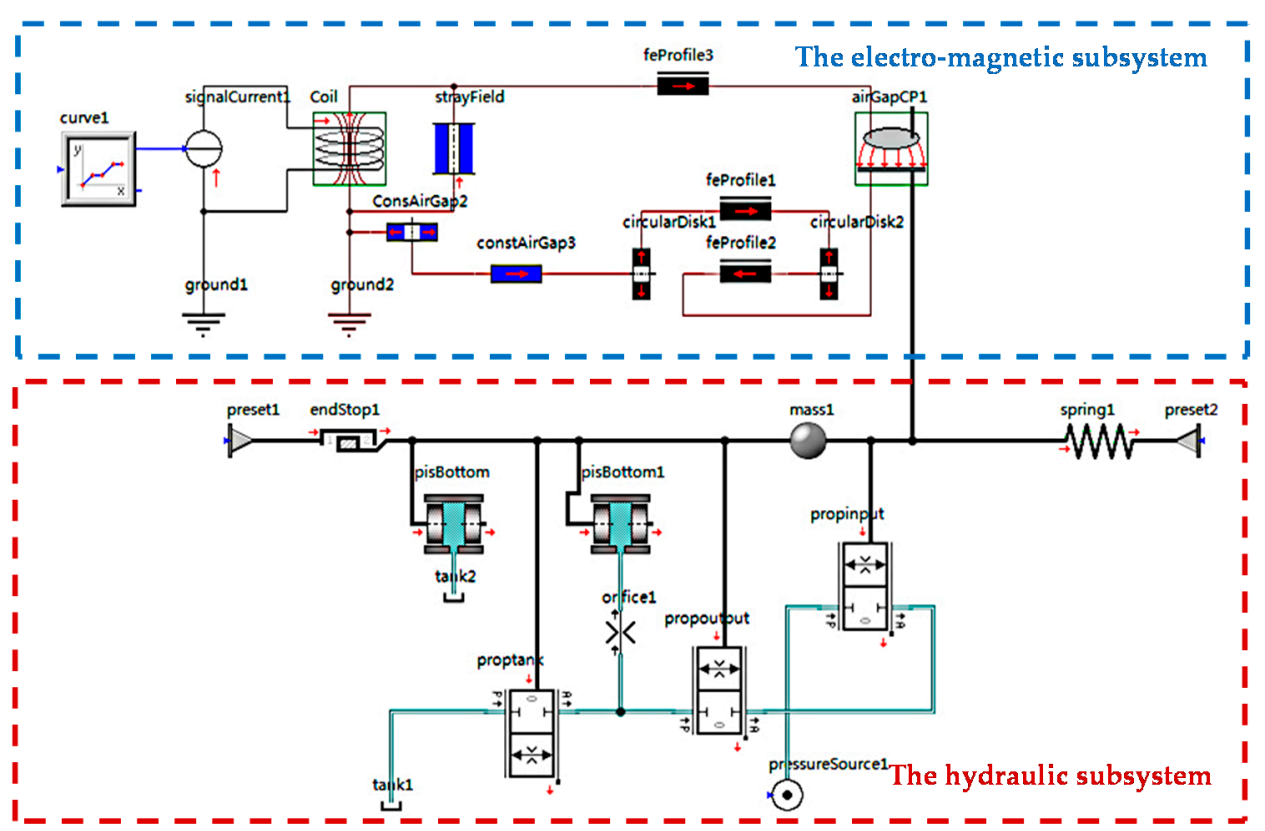

Figure 5. Modeling of the direct operating solenoid valve.

\subsection{Validation of Model}

To evaluate the performance of the simulation model of the direct operating solenoid valve, the laboratory testing is conducted to make the comparison with simulation results. Figure 6 provides the schematic diagram of the test rig 12. It is comprised of a heat exchanger 1 manufactured by Siemens(Berlin, Germany), an oil filter 2, a motor (also by Siemens), an oil pump 3 whose rated power is $13.6 \mathrm{~kW}$, a reservoir, a TCU 5, an external computer 4 and a fixture 11 where the direct operating solenoid valve inserted in. The pressure of the control port is measured by a pressure sensor 9 (Sensata, Attleboro, MA, USA) which has a measuring range of 0-2.5 MPa. And the flow rate is obtained by a flow meter 6 (Hydrotechnik, Limburg, Germany) ranging from $7.5 \mathrm{~L} / \mathrm{min}$ to $30 \mathrm{~L} / \mathrm{min}$. The automatic transmission fluid used in the test is Dexron IV from local supplier.

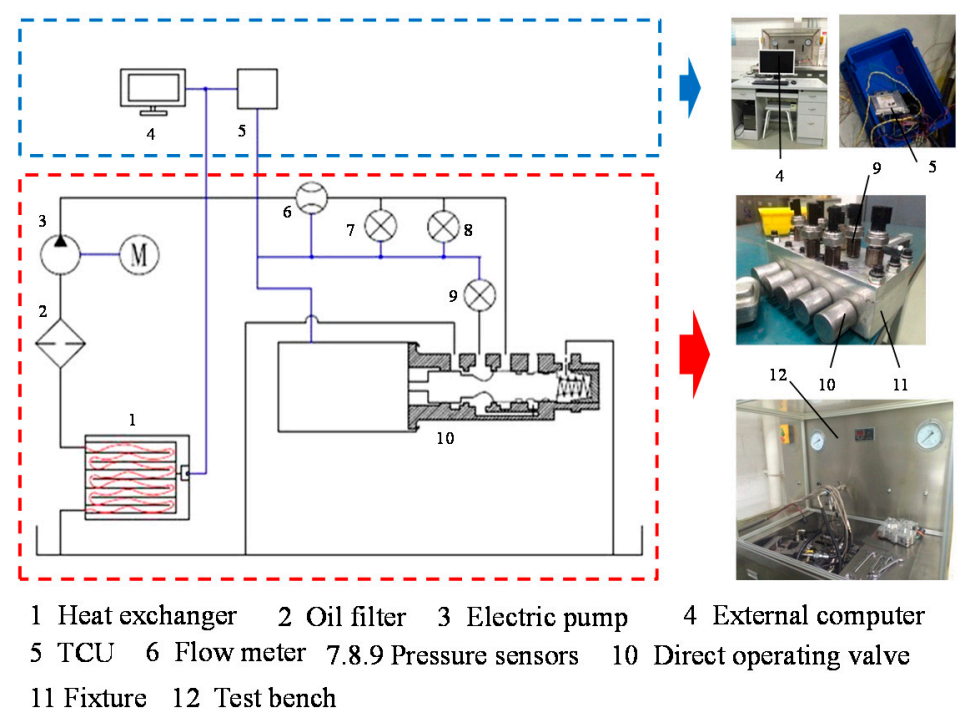

Figure 6. Schematic diagram and photos of experimental test rig. 
The principle of the hydraulic circuit can be simply described as follows. High pressure hydraulic fluid was supplied from the mechanic pump driven by the motor to the direct operating solenoid valve 10 installed in a tailor made fixture 11. The control pressure of the solenoid valve spool was controlled by the input signal sent by the computer and transferred by the transmission control unit (TCU) to the electromagnetic unit. The control pressure, which is a most important feature to verify the simulation model as well as analyze the valve dynamic characteristics, was displayed in the computer collected by the pressure sensor and converted by TCU.

Comparison was made between the measured and simulated pressure at the control port. The input current which is extracted from the actual control signal is shown in Figure 7. The current begins with a peak up to $600 \mathrm{~mA}$ to activate the spool within $0.01 \mathrm{~s}$. After $0.14 \mathrm{~s}$, the electric current returns to $300 \mathrm{~mA}$ and holds for $1 \mathrm{~s}$. From $1.16 \mathrm{~s}$ to $11.16 \mathrm{~s}$, the electric current increases linearly to $1000 \mathrm{~mA}$ and maintains for another $1 \mathrm{~s}$. Finally, the electric current declines to 0 from $12.16 \mathrm{~s}$ to $28.29 \mathrm{~s}$.

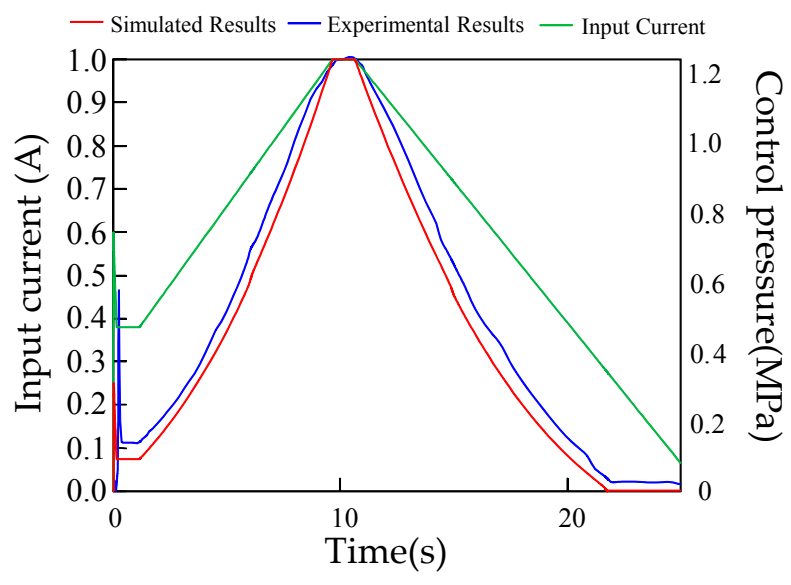

Figure 7. Comparison of experimental and numerical control pressure in the direct operating solenoid valve.

Both the simulated and measured control pressure at the control port is illustrated in Figure 7. It is obvious that the maximum pressure in the simulation result is the same with that in the experimental one. And there is a good agreement between the two curves with about only $4 \%$ error of the slope. Moreover, the pressure response time and the time when the pressure disappears are completely consistent. Therefore, the experimental result confirms the correctness of the model. The pressure difference is within $0.1 \mathrm{MPa}$, which is probably caused by the equipment error.

\section{Results and Discussion}

The response time and the leakage flow are two of the most important characteristic indicators of the solenoid valve. Analysis has been conducted for the two characteristics of the direct operating solenoid valve.

\subsection{Analysis of Pressure Response}

Figure 8 shows the curves of the control pressure and the spool displacement. In the initial opening process of the direct operating solenoid valve from $0-0.38 \mathrm{~s}$, the pressure greatly rises up because the spool suddenly moves fast. And the movement of the spool keeps the opening area of the control port almost the same so that the pressure increases smoothly during the next $0.5 \mathrm{~s}$. Finally, the pressure goes down with the closing command and the spool returns back. 


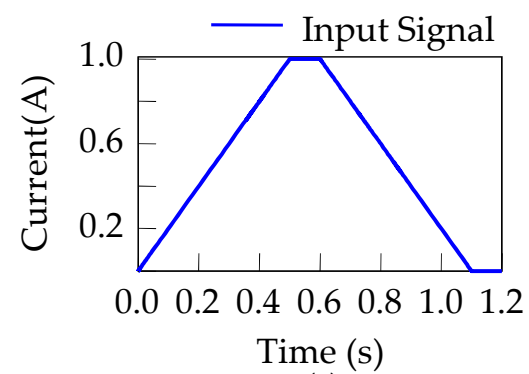

(a)

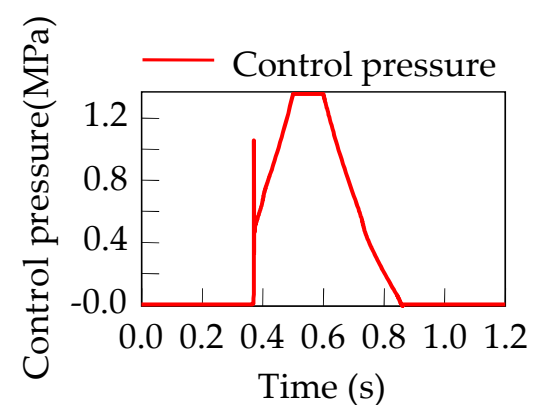

(b)

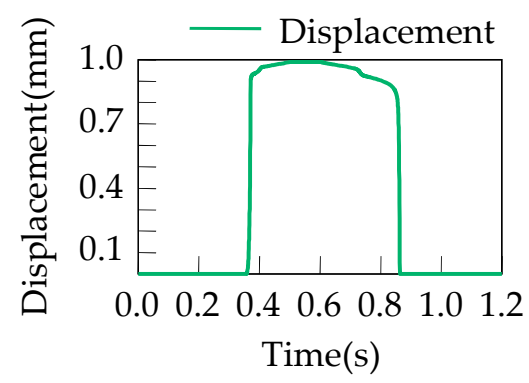

(c)

Figure 8. Control pressure and displacement of the valve. (a) Input signal (b) Control pressure (c) Spool displacement.

Since the motion of the valve is determined by the resultant force on the valve, all forces acting on the spool as well as the spool displacement are depicted in Figure 9. The spool remains still in the range of 0 to $0.4 \mathrm{~s}$ because the increasing magnetic force is smaller than the composition of the spring force and the viscous force. And there is no feedback force due to the closure of the input port. Once the magnetic force is big enough, the spool moves immediately after there appears the feedback force.

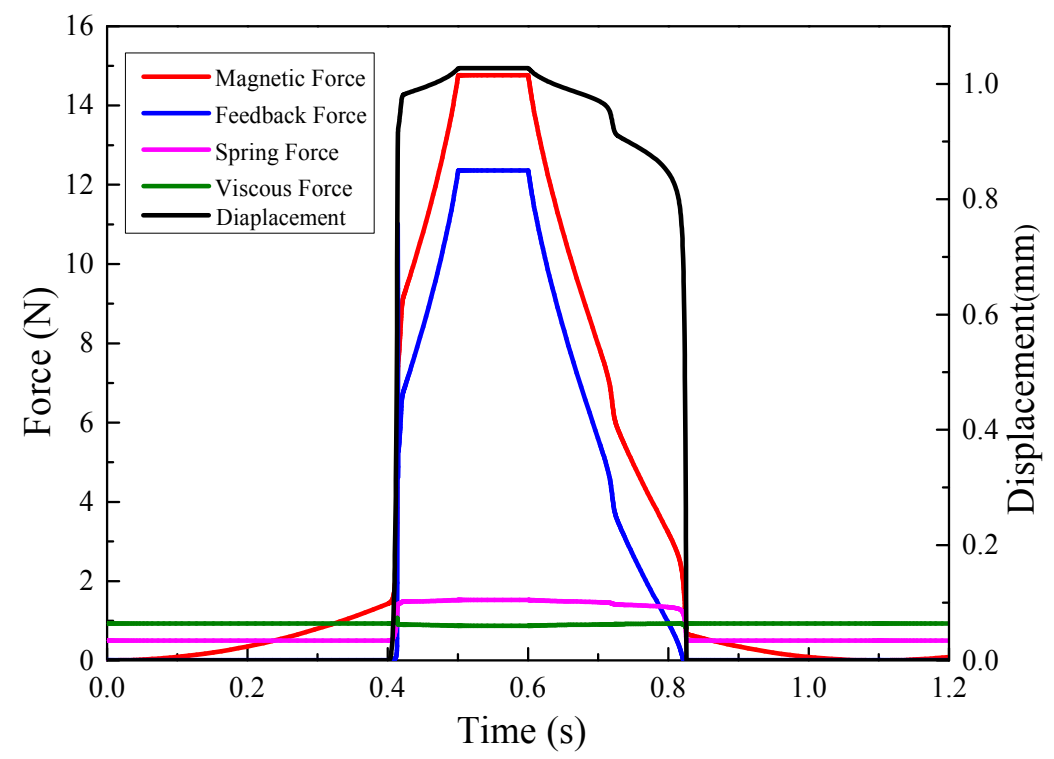

Figure 9. Forces on the spool and valve displacement.

Further analysis on the forces is conducted combining Figures 9 and 10. There are spring force called preload force before the spool starts to move, and viscous force acting on the spool when without current. The preload force comes from the spring compression. When leakage flows through the 
sleeve and spool, the viscous force is generated by the leakage from the supply port to the control port. When the electric current is input, the magnetic force grows up and becomes larger than the preload force at $0.32 \mathrm{~s}$.

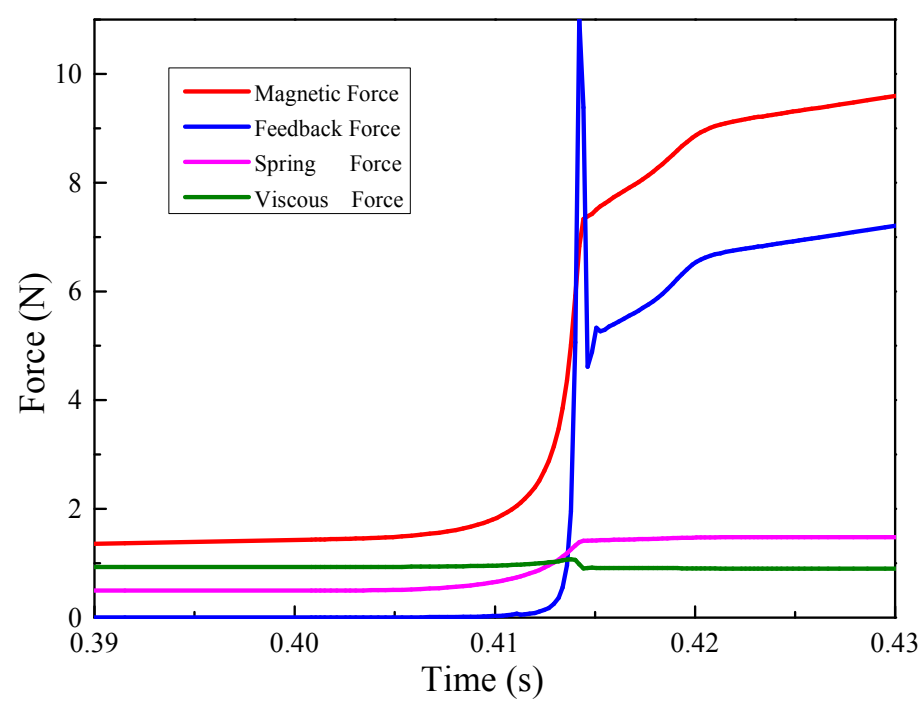

Figure 10. Forces acting on the spool during $0.4-0.43 \mathrm{~s}$.

As the magnetic force grows large enough to overcome the preload force combined with the viscous force, the force balance is thrown off and the spool starts to move against the spring and the spring is compressed, which causes the spring force to rise. When the supply port is connected to the control port, the fluid flows through to the clutch. Meanwhile, the feedback force appears at $0.41 \mathrm{~s}$ to hinder the opening of the control port and changes with the control pressure. At the opening phase of the control port, the feedback force heavily fluctuates due to the sharp increase of the feedback pressure. Since different force changes at different speed, the acceleration is not constant and the displacement of the spool varies. It is worth noting that the magnetic force will vary with the input current during the spool movement and remain the similar variation trend with the control pressure.

It can be observed that the active force on the spool is the magnetic force. The passive forces on the spool are the spring force, the viscous force and the feedback force. The motion state of the valve depends on the resultant force acting on the spool and can be divided into three phases: (1) Stationary state. There is only spring force acting on the spool. (2) Moving tendency. The magnetic force, spring force and the viscous force apply on the spool. However, the magnetic force is in the opposite direction to the spring and viscous forces. The control port is still closed. (3) Motion state. The feedback force arises in the feedback chamber since the control port is connected to the supply port. The spool begins to move under the action of the magnetic force, the spring force, the viscous force and the feedback force.

The pressure and flow response characteristics are important indicators of the performance of the direct operating solenoid valves. A faster response characteristic is not the better one, because the pressure overshoot will be amplified if the response is too fast. However, the response delay will lead to the reduction of the control accuracy. The response characteristics are mainly dependent on the spool motion state which mostly relies on the resultant force on the valve.

In order to improve the pressure response time, the spool motion should be started earlier in order to reach force balance. This target can be reached by increasing the active force or decreasing the passive force. The spool will move earlier if the preload force and the viscous force diminished. Moreover, the control port could be more quickly opened if the spring stiffness decreases. Nevertheless, the spring was not analyzed in this paper as it is an optional product. More research will be done on the magnetic force and the viscous force in the further. 


\subsection{Analysis of Forces}

The magnetic force is the main driving force acting on the solenoid valve which would significantly influence the pressure response time. Meanwhile the response time will change with the variation of the magnetic force.

The critical structure of the magnetic part that impacts on the magnetic force was analyzed using the model proposed in this paper. The air gap in the magnetic part transfers forces generated by the magnetic part to the mechanical part. Different diameters of the air gap are set in the model and the results are shown in Figure 11.

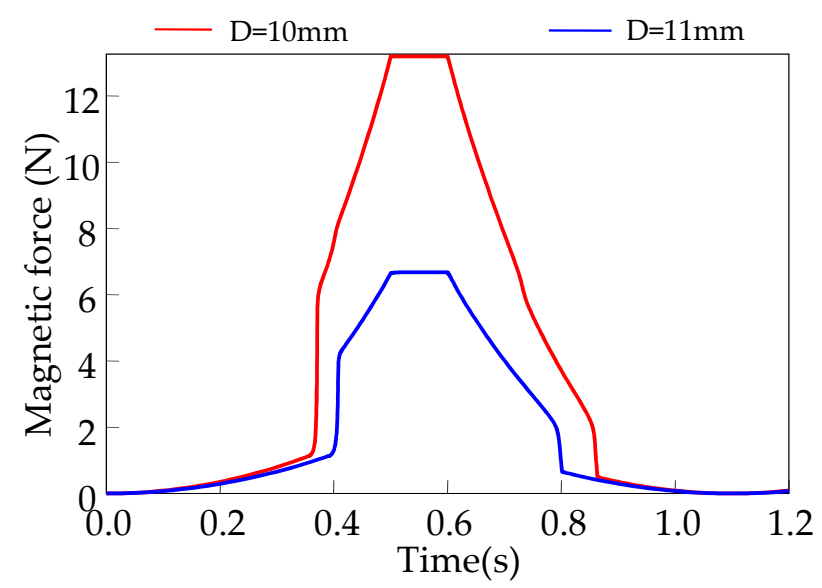

Figure 11. Magnetic force in different air gap.

It can be obviously observed that smaller air gap leads to bigger peak value and faster change of the magnetic force. The magnetic forces are almost accordant at the beginning and the ending of the time. However, the force in $10 \mathrm{~mm}$ rises up earlier than that in $11 \mathrm{~mm}$. Higher maximum value in $10 \mathrm{~mm}$ gives rise to larger slope of the magnetic force curve.

Figure 12 presents the static characteristics of the magnetic force in different current. It indicates that the magnetic force is almost unchanged with the displacement at the same current. Slight skewing is confined within $0.5 \mathrm{~N}$. Because the magnetic force is generated by the electric current and has no connection with the displacement, slight skewing increases with the growing current. However, the motion of the armature will have a small influence on the magnetic field which could result in the slight change of the magnetic force during the spool movement.

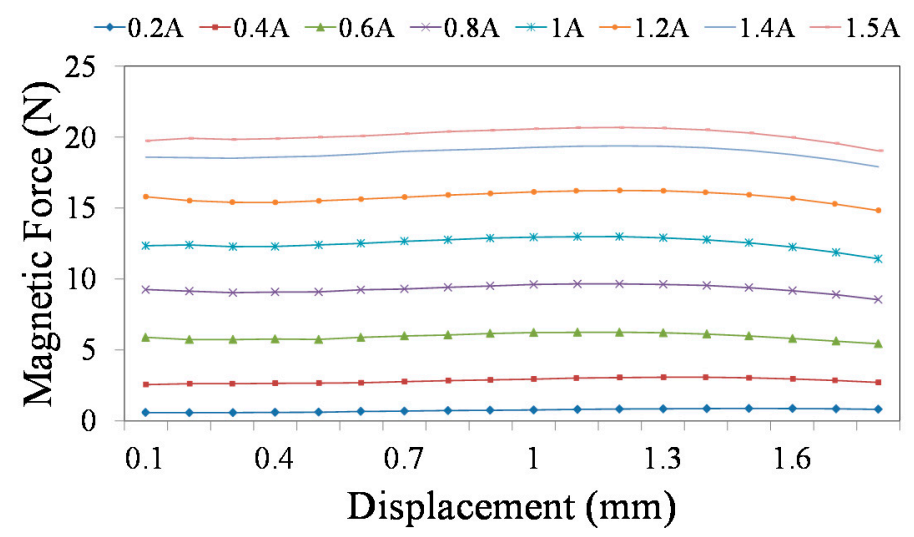

Figure 12. The static characteristics of the magnetic force as a function displacement for different electric current. 
The static viscous force appears when the spool has the tendency of motion. And the dynamic force derives from the relative movement between the spool and the sleeve when the fluid flows through. Although small, the viscous force cannot be neglected because the force balance which determines the pressure response characteristics will change with it. Figure 13 illustrates the effect of the viscous force on the control pressure.

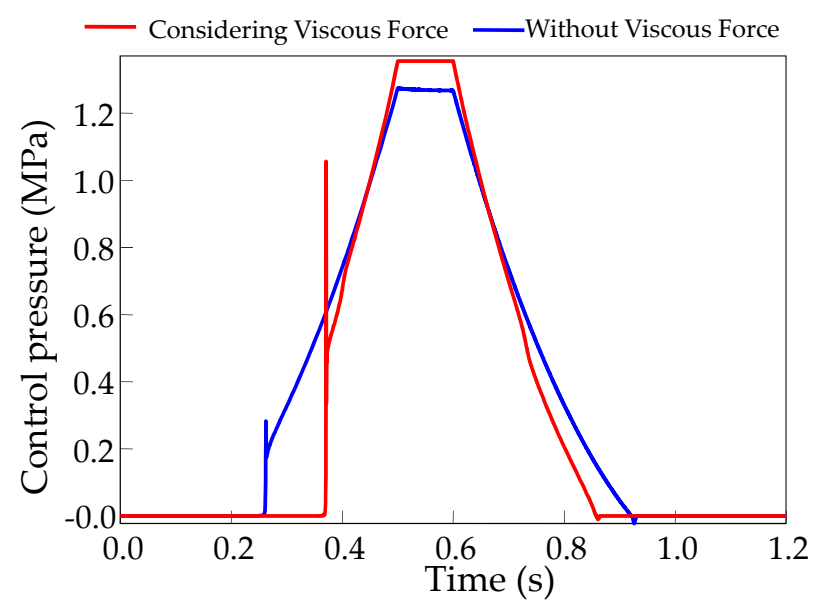

Figure 13. Control pressure in the valve.

The control pressure almost equals to 0 before $0.37 \mathrm{~s}$ when considering the viscous force, which means that the viscous force hinders the rise of the control pressure.

Different clearance height is considered in the model and the results are shown in Figures 14-16. The static viscous force grows with the increase of the clearance height. The static viscous force in $10 \mu \mathrm{m}$ is $0.32 \mathrm{~N}$ while the viscous force in $30 \mu \mathrm{m}$ is $0.94 \mathrm{~N}$ which indicates the viscous force will increase when the size of the clearance is increased. Meanwhile the dynamic viscous force will rapidly increase or decline when there is sudden change in the spool velocity. However, the greater the spool velocity changes, the smaller the dynamic viscous force varies because fast spool velocity thins the oil film.

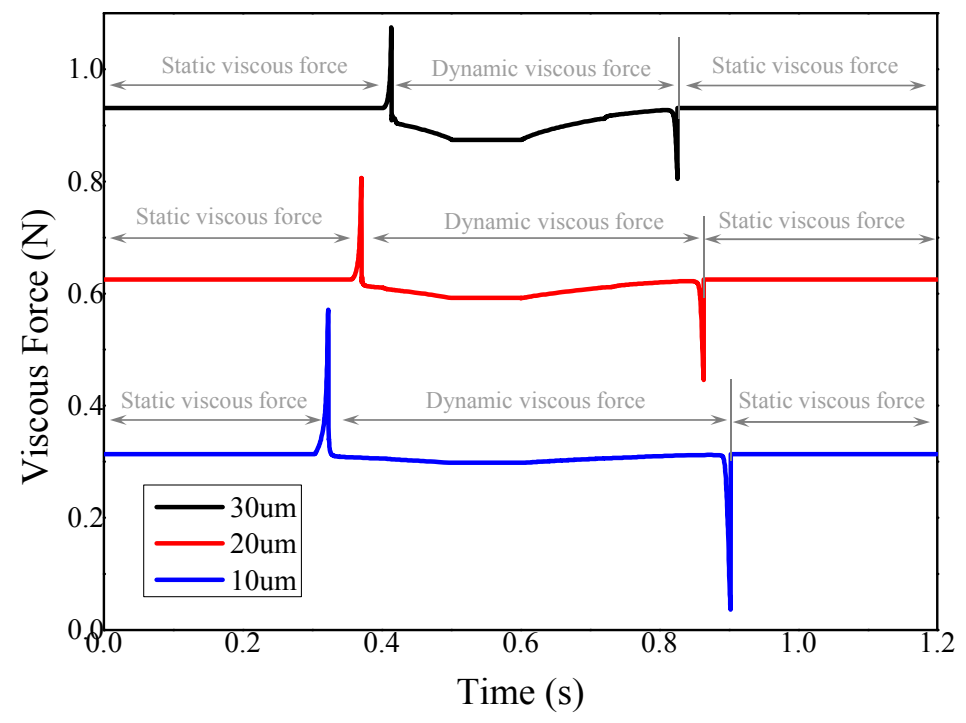

Figure 14. Viscous force for different clearance. 


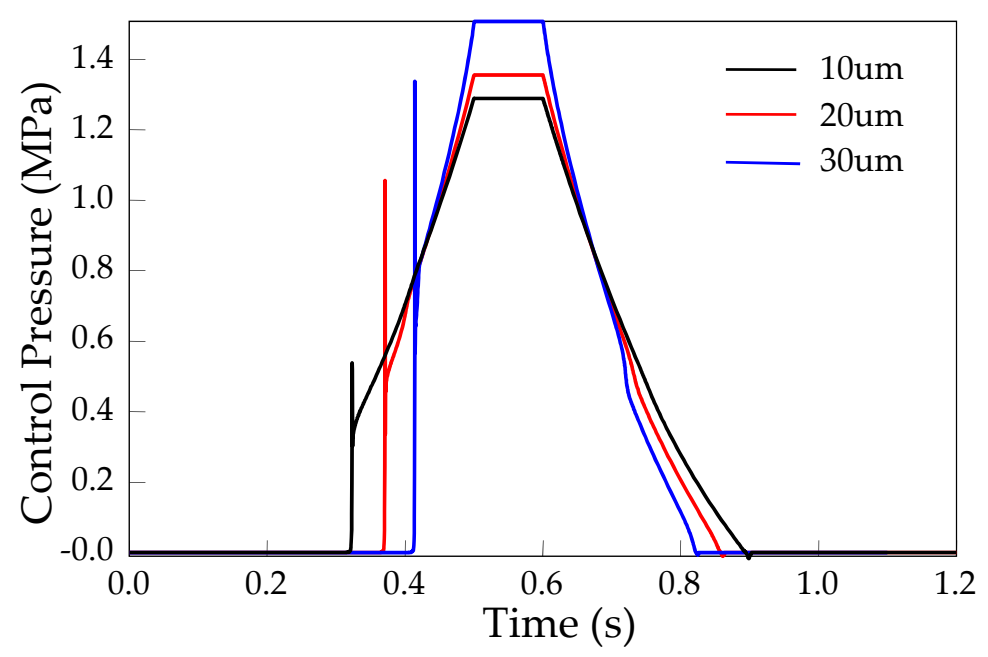

Figure 15. Control pressure for different clearance.

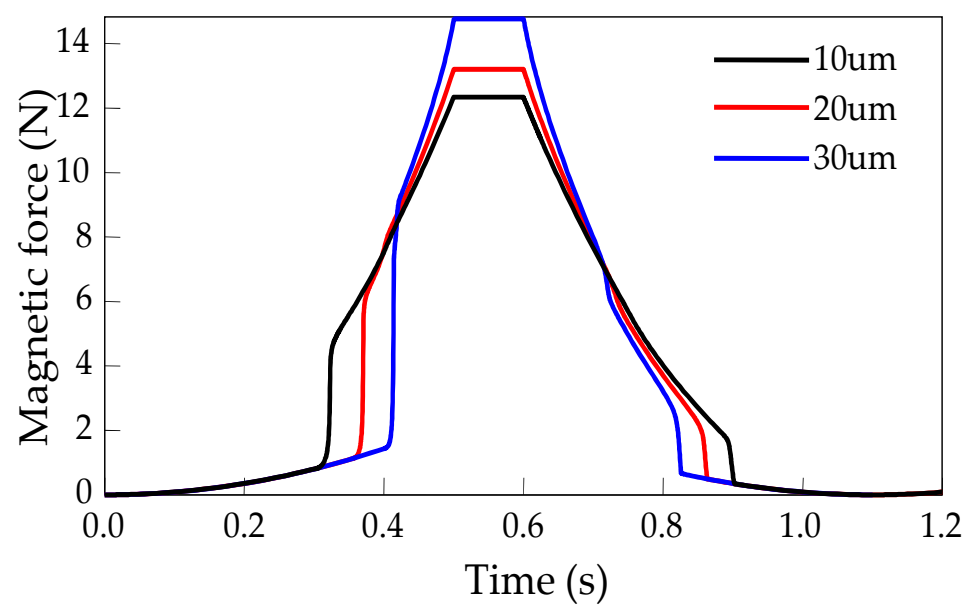

Figure 16. Magnetic force for different clearance.

One noticeable observation is that the magnetic force response becomes slower with the increase of the clearance. On the contrary, the height of the clearance contributes to the maximum value of the magnetic force. The same is true for the pressure response and the maximum pressure. Comparing the magnetic force with the pressure response in the same clearance, it can be found that both of them have the same variation tendency. Hence, the magnetic force has a direct influence on the control pressure.

Figures 15 and 17 show the relation between the feedback force and the control pressure. The feedback force and its growth rate rise with the growing clearance height which indicates that the initial velocity and opening area of the valve are augmented due to the variation of the equilibrium point of the resultant force. What is more, the spool displacement rises which can also lead to larger valve opening area. Therefore, the clearance height is a key factor that influences on the control pressure, because the control pressure is in direct proportion to the valve opening area. 


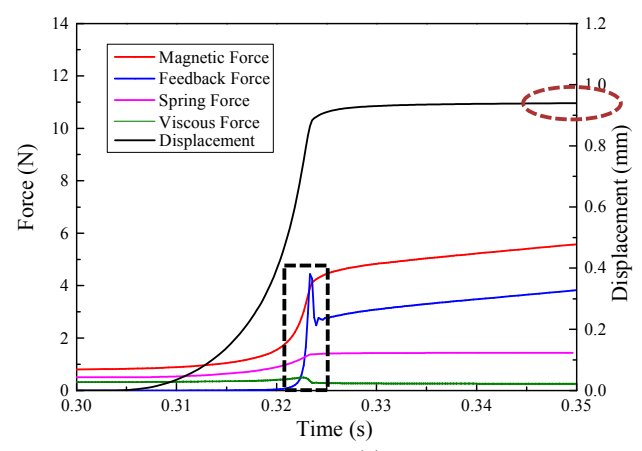

(a)

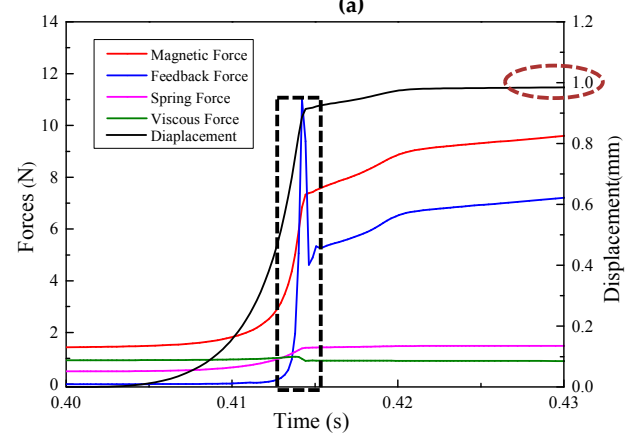

(c)

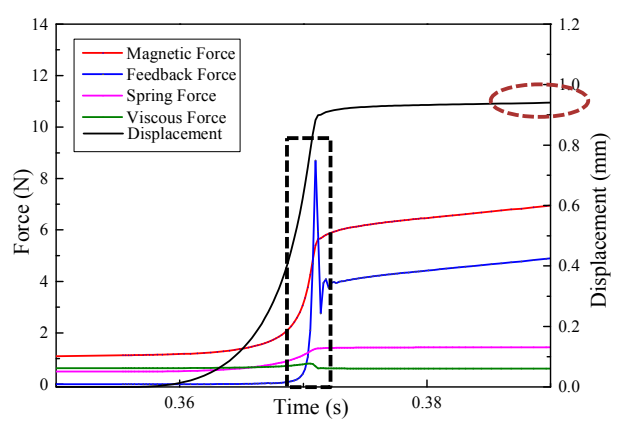

(b)

Figure 17. (a) Forces on the valve and the spool displacement in $10 \mu \mathrm{m}$ (b) Forces on the valve and the spool displacement in $20 \mu \mathrm{m}$ (c) Forces on the valve and the spool displacement in $30 \mu \mathrm{m}$.

Figure 17 shows that the growth rate of the magnetic force increases with the clearance height while that of the viscous force and that of the spring force remain unchanged before the spool starts to move. As the magnetic force is much larger than the other two forces, the positive acceleration of the valve with higher clearance is larger than that with smaller one (Figure 18), which would induce longer displacement of the spool (Figure 19). During spool motion, the control pressure grows with the valve opening area, leading to the increasing pressure in the feedback chamber connected with the control port combining Figures 15 and 19. Hence, the feedback force and its growth rate both rise with the growing clearance height (Figure 17). Since the feedback force hinders the spool movement, the negative acceleration goes up with the increasing clearance height. According to Newton's second law, the value of the spool acceleration could be quite high because the spool is only $7.39 \mathrm{~g}$.

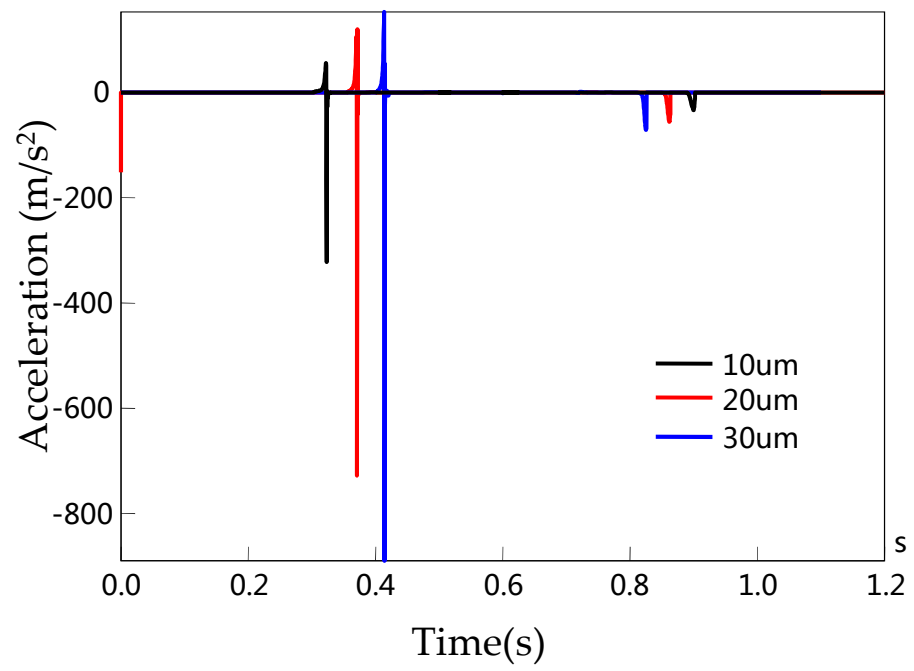

Figure 18. Spool acceleration for different clearance. 


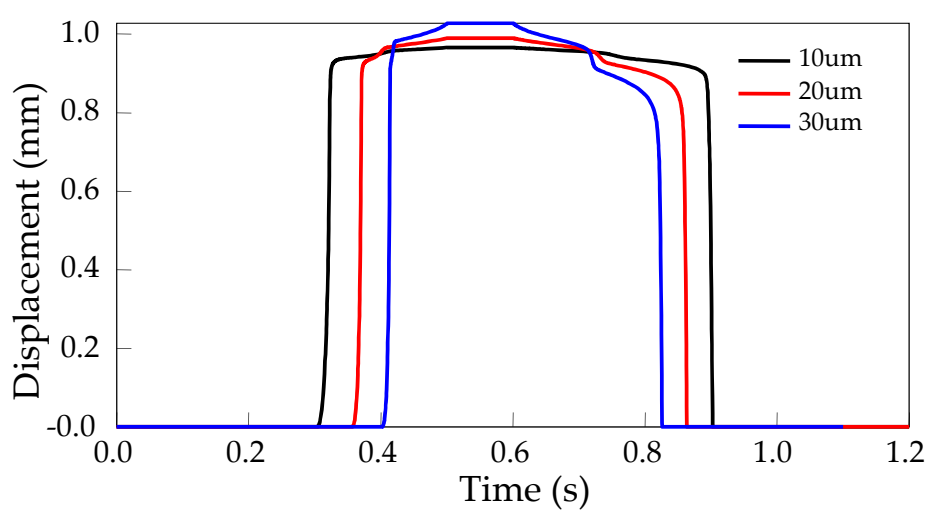

Figure 19. Spool displacement for different clearance.

The force of inertia mainly influences the stability and the responsiveness of the valve during spool movement. If the force of inertia is too small, the spool will be very sensitive to the change of the resultant force, resulting in frequent changes of the spool motion state. The force of inertia helps the spool maintain a relatively stable movement trend and prevent vibration when the dynamic forces acting on the spool are constantly changing. In the hydraulic control circuit of an automatic transmission, the vibration of the spool can easily give rise of the pressure fluctuation which greatly reduces the shifting quality. In addition, it is hard for the hydraulic control circuit to converge because of the superposition of spool vibration.

On the contrast, if the force of inertia is too large, the motion response of the valve will be delayed because the spool is insensitive to the change of the resultant force. The delayed motion response will result in both delayed control response and the increase of the overshoot in the hydraulic circuit. Therefore, the force of inertia is of great importance because it directly affects the control quality on the spool motion state.

Thus, the maximum control pressure is enhanced when the displacement increased. The maximum control pressure will increase from 1.2 $\mathrm{MPa}$ to $1.5 \mathrm{MPa}$ if the displacement grows from $0.9 \mathrm{~mm}$ to $1.1 \mathrm{~mm}$. It could be easily deduced from the analysis that the magnetic force plays a main role in all the forces which could influence the control pressure of the valve.

The starting time of the control pressure delays $0.1 \mathrm{~s}$ in the $30 \mu \mathrm{m}$ comparing to that in the $10 \mu \mathrm{m}$ as shown in Figure 15. As the movement of the valve starts only if the force balance is reached, the valve with small clearance height starts earlier than that with bigger one. The time that all forces reach to a balance is when the control pressure appears because the control port has been opened due to the displacement of the spool. Therefore, both the leakage and the pressure response should be taken into consideration when designing the clearance.

\subsection{Analysis of Leakage Flow}

Leakage is one of the inevitable problems for the automatic transmission which would give rise to pressure loss, waste of ATF, fluid insufficient, etc. The leakage flow has an important influence on the direct operating solenoid valve. Firstly, the leakage flow will directly affect the response characteristics of the solenoid valves, including pressure response and output flow. If the leakage flow is too large, the actual output flow will be less than the control flow which can't meet the requirement of both the flow and the pressure. At this point, the oil filling time of the clutch will be extended which leads to the delay of the pressure response time. As a result, the shifting time will be prolonged and the shifting quality will be reduced. Secondly, large leakage in the solenoid valve will reduce the efficiency of the automatic transmission. Thereby, it affects the fuel consumption of the vehicle.

Although a small leakage has been achieved in the direct operating solenoid valve, it cannot be completely avoided. The leakage in the direct operating solenoid valve is mainly caused by the clearance between the spool and the sleeve. The clearance height which is the most important 
parameter affecting the leakage flow in the solenoid design is usually between $20 \mu \mathrm{m}-40 \mu \mathrm{m}$. A good clearance design is actually accurate design of the machining tolerance and the assembly tolerance of both the valve spool and the sleeve. Small clearance height will raise the requirements of the processing technique and the assembly technique, so it will significantly increase the cost. Meanwhile, it is averse to the quality control because high processing requirements will increase the product reject ratio which brings down the production efficiency.

It is hard for small clearance to keep the oil slick between the spool and the sleeve. Once the oil slick is broken during relative motion, the surface of the components is easily scratched because of dry friction. In addition, small clearance would frequently result in clamping stagnation. Thus, the solenoid valve falls into control failure. Although big clearance could not only decrease the cost but cut down the risk of clamping stagnation, the unavoidable large leakage will greatly reduce energy efficiency and bring about poor pressure response.

Since the clearance height between the spool and the sleeve has a direct effect on the performance of the direct operating solenoid valve. It is necessary to balance the energy efficiency, manufacturing technique and quality control. In order to analyze the effect of the clearance, the leakage from different height of clearance is depicted in Figure 20.

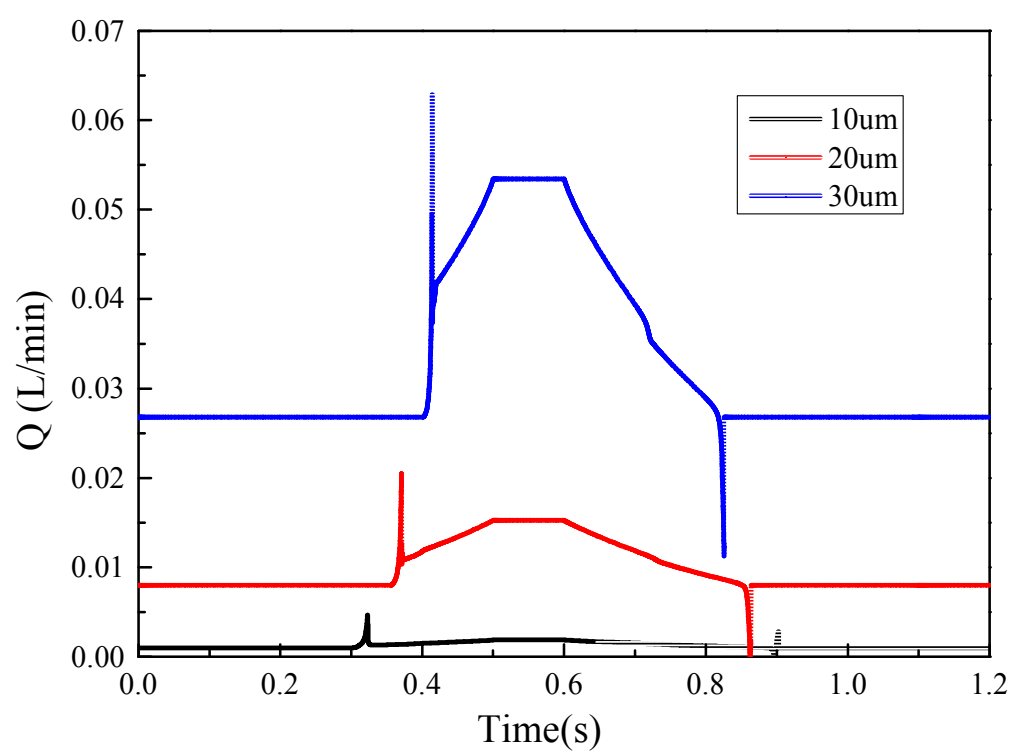

Figure 20. Leakage flow characteristics in the direct operating solenoid valve for different clearance.

Figure 20 describes that the maximum leakage in $30 \mu \mathrm{m}$ is $0.06 \mathrm{~L} / \mathrm{min}$ and the leakage reduces rapidly with the decrease of the clearance. It is observed that the solenoid valve with smaller clearance height has not only less leakage but faster pressure response when considering both Figures 15 and 20. The leakage flow is of same variation trend with the control pressure at the same clearance height. To make a further study, the clearance between the spool and the sleeve could be considered as an orifice when controlling the other variables constant. The pressure difference between the control port and the exhaust port will increase with the growing control pressure, and vice versa. According to Equation (18),

$$
Q_{\text {orifice }}=C_{d} \pi r_{\text {orifice }}^{2} \sqrt{\frac{2}{\rho}|\Delta p|}
$$

where $Q_{\text {orifice }}$ is the flow through the orifice, $r_{\text {orifice }}$ is the radius of the orifice, $\Delta p$ is the pressure difference at both ends of the orifice.

Hence, the flow is in proportion to the pressure difference at both ends of the orifice. As a result, the leakage flow changes with the control pressure. 
In our initial 8AT product, the leakage in the conventional clutch control unit consisting of two solenoid valves and one mechanical valve is usually $0.15 \mathrm{~L} / \mathrm{min}$ which can be reduced by $60 \%$ if the control unit is replaced by a direct operating solenoid valve.

\section{Conclusions}

This paper proposed a new numerical approach solving the multi-domain physical problem of the direct operating solenoid valve. A precise model of the valve was developed to investigate the performance of the direct operating solenoid valve. The accuracy of the simulation results was verified by the experimental data in the test rig. Effect of various forces, including the magnetic force, the spring force, the viscous force, the feedback force on the pressure response of the direct operating solenoid valve were investigated. Furthermore, the influences on the dynamic characteristics of the valve were analyzed based on the model. The leakage flow in different clearance has been compared. As a consequence, the conclusions can be drawn:

(1) The simulation results of this study agreed with the experimental results. Thus, the mathematical model developed in this study was effective and accurate.

(2) Both the magnetic force and the viscous force had significantly influence on the pressure response. The pressure response time would be shortened if the magnetic force responded faster or the viscous force was reduced.

(3) To improve the response time of the solenoid valve, the clearance height should be reduced. The resultant force on the spool in $10 \mu \mathrm{m}$ would reach the equilibrium point $0.1 \mathrm{~s}$ earlier than that in $30 \mu \mathrm{m}$.

(4) The clearance height was proved to have great influence on the leakage of the solenoid valve. The leakage increases with the growing clearance height, which showed the leakage in $30 \mu \mathrm{m}$ was triple the amount of that in $20 \mu \mathrm{m}$.

(5) The leakage of the shifting control system employing the direct acting solenoid valve can be reduced by $60 \%$ compared to the conventional two-stage pilot valve in our previous product.

This paper could benefit the researchers dealing with the direct operating solenoid valve design for pressure smooth control and energy conservation in the shifting control system of an automatic transmission.

Acknowledgments: This work was supported by the National Natural Science Foundation of China (grant number 51405010).

Author Contributions: Xiao Han and Yanfang Liu designed and conducted the experiments and wrote the paper. Xiangyang $\mathrm{Xu}$ is the research advisor, who proposed the structure of the paper. Yanjing Liu and Yang Liu were responsible in improving of the quality of this article.

Conflicts of Interest: The authors declare no conflict of interest.

\section{References}

1. Wu, S.; Jiao, Z.; Yan, L.; Zhang, R.; Yu, J.; Chen, C.Y. Development of a direct-drive servo valve with high-frequency voice coil motor and advanced digital controller. IEEE/ASME Trans. Mechatron. 2014, 19, 932-942. [CrossRef]

2. Schultz, A. Transient Simulation to Improve the Solenoid Dynamic in Pneumatic Valves. Ph.D. Thesis, Institute for Fluid Power Drives and Controls of RWTH, Aachen, Germany, 2004.

3. Wang, Z. Optimum Research on the Great Flow and Fast Response Electromagnetic Valve Used in the Medium Pressure Common Rail System of Diesel Engine. Master's Thesis, Wuhan University of Technology, Wuhan, China, 2006.

4. Liu, Q.; Bo, H.; Qin, B. Design and analysis of Direct Action Solenoid Valve. At. Energy Sci. Technol. 2010, 44, 706-711.

5. Shin, Y.; Lee, S.; Choi, C.; Kim, J. Shape optimization to minimize the response time of direct-acting solenoid valve. J. Magn. 2015, 20, 193-200. [CrossRef] 
6. Lee, G.S.; Sung, H.J.; Kim, H.C.; Lee, H.W. Flow force analysis of a variable force solenoid valve for automatic transmissions. J. Fluids Eng. 2010, 132, 031103. [CrossRef]

7. Mutschler, K.; Dwivedi, S.; Kartmann, S.; Bammesberger, S.; Koltay, P.; Zengerle, R.; Tanguy, L. Multi physics network simulation of a solenoid dispensing valve. Mechatronics 2014, 24, 209-221. [CrossRef]

8. Liu, Y.; Dai, Z.; Xu, X.; Tian, L. Multi-domainmodelingandsimulationofproportionalsolenoidvalve. J. Cent. South Univ. 2011, 18, 1589-1594. [CrossRef]

9. Liu, Z.; Han, X.; Liu, Y. Dynamic Simulation of Large Flow Solenoid Valve. In Proceedings of the ASME 2016 International Mechanical Engineering Congress and Exposition, Phoenix, AZ, USA, 11-17 November 2016; ASME: New York, NY, USA, 2016; p. V009T012A015.

10. Xiong, Y.; Wei, J.; Feng, R. Adaptive robust control of a high-response dual proportional solenoid valve with flow force compensation. Proc. Inst. Mech. Eng. Part I J. Syst. Control Eng. 2015, 299, 3-26. [CrossRef]

11. Zhu, Y.; Jin, B. Analysis and modeling of a proportional directional valve with nonlinear solenoid. J. Braz. Soc. Mech. Sci. Eng. 2015, 2, 1-8. [CrossRef]

12. Liu, L.; Zhang, D.; Zhao, J. Design and research for the water medium low pressure large-flow pilot operated solenoid valve. Strojniski Vestnik 2014, 60, 10.

13. Park, C.D.; Lim, B.J.; Chung, K.Y. Design verification methodology for a solenoid valve for industrial applications. J. Mech. Sci. Technol. 2015, 29, 677-686. [CrossRef]

14. Wang, L.; Li, G.X.; Xu, C.L.; Xi, X.; Wu, X.J.; Sun, S.P. Effect of characteristic parameters on the magnetic properties of solenoid valve for high-pressure common rail diesel engine. Energy Convers. Manag. 2016, 127, 656-666. [CrossRef]

15. Zhao, J.; Fan, L.; Liu, P.; Grekhov, L.; Ma, X.; Song, E. Investigation on electromagnetic models of high-speed solenoid valve for common rail injector. Math. Probl. Eng. 2017, 2017, 1-10. [CrossRef]

16. Walker, P.D.; Zhu, B.; Zhang, N. Nonlinear modeling and analysis of direct acting solenoid valves for clutch control. J. Dyn. Syst. Meas. Control 2014, 136, 562-576. [CrossRef]

17. Shi, Y.; Wu, T.; Cai, M.; Wang, Y.; Xu, W. Energy conversion characteristics of a hydropneumatic transformer in a sustainable-energy vehicle. Appl. Energy 2016, 171, 77-85. [CrossRef]

18. Shi, Y.; Wang, Y.; Liang, H.; Cai, M. Power characteristics of a new kind of air-powered vehicle. Int. J. Energy Res. 2016, 40, 1112-1121. [CrossRef]

19. Shi, Y.; Wu, T.; Cai, M.; Liu, C. Modelling and study on the output flow characteristics of expansion energy used hydropneumatic transformer. J. Mech. Sci. Technol. 2016, 30, 1163-1170. [CrossRef]

20. Cai, M.; Wang, Y.; Shi, Y.; Liang, H. Output dynamic control of a late model sustainable energy automobile system with nonlinearity. Adv. Mech. Eng. 2016, 8, 1-11. [CrossRef]

21. Xu, Q.; Cai, M.; Shi, Y. Dynamic heat transfer model for temperature drop analysis and heat exchange system design of the air-powered engine system. Energy 2014, 68, 877-885. [CrossRef]

22. Xu, Q.; Shi, Y.; Yu, Q.; Cai, M. Virtual prototype modeling and performance analysis of the air-powered engine. ARCHIVE Proc. Inst. Mech. Eng. Part C J. Mech. Eng. Sci. 2014, 228, 2642-2651.

23. Yu, Q.; Cai, M.; Shi, Y. Working characteristics of two types of compressed air engine. J. Renew. Sustain. Energy 2016, 8, 397-411. [CrossRef]

24. Shi, Y.; Cai, M. Dimensionless study on output flow characteristics of expansion energy used pneumatic pressure booster. J. Dyn. Syst. Meas. Control 2013, 135, 021007. [CrossRef]

25. Yu, Q.; Cai, M.; Shi, Y.; Yuan, C. Dimensionless study on efficiency and speed characteristics of a compressed air engine. J. Energy Resour. Technol. 2015, 137, 044501-044509. [CrossRef]

(C) 2017 by the authors. Licensee MDPI, Basel, Switzerland. This article is an open access article distributed under the terms and conditions of the Creative Commons Attribution (CC BY) license (http://creativecommons.org/licenses/by/4.0/). 